\title{
A Neurotrophic Factor Receptor GFRA2, a Specific Surface Antigen for Cardiac Progenitor Cells, Regulates the Process of Myocardial Compaction
}

\author{
Hidekazu Ishida, Shigeru Miyagawa, Keiichi Ozono, \\ Ken Suzuki, Yoshiki Sawa, and Kenta Yashiro
}

\author{
Keywords \\ GFRA2 - Surface antigen - Cardiac progenitor cells · Non-compaction \\ cardiomyopathy
}

A surface marker specific for cardiac progenitors (CPs) allows the robust isolation of CPs, effectively circumventing the necessity of genetic modification. Recently, we have reported that glial cell line-derived neurotrophic factor receptor alpha 2 (Gfra2), which is anchored to the plasma membrane via Glycosylphosphatidylinositol, specifically marks CPs of both the first and second heart fields within the early mouse embryo [1], identified by single-cell expression profiling on mouse embryonic CPs (Fig. 56.1) [2, 3].

\footnotetext{
H. Ishida $\cdot$ K. Ozono

Department of Paediatrics, Graduate School of Medicine, Osaka University,

Suita, Osaka, Japan
}

\section{S. Miyagawa $\cdot$ Y. Sawa}

Department of Cardiovascular Surgery, Graduate School of Medicine, Osaka University,

Suita, Osaka, Japan

K. Suzuki

Centre for Microvascular Research, William Harvey Research Institute, Barts and The

London School of Medicine and Dentistry, Queen Mary University of London, London, UK

K. Yashiro $(\bowtie)$

Department of Cardiac Regeneration and Therapeutics, Graduate School of Medicine, Osaka University, Suita, Osaka, Japan

Centre for Endocrinology, William Harvey Research Institute, Barts and The London School of Medicine and Dentistry, Queen Mary University of London, London, UK

Department of Anatomy, Division of Anatomy and Developmental Biology, Kyoto Prefectural University of Medicine, Kyoto, Japan

e-mail: kyashiro@kotp.kpu-m.ac.jp 


\section{Mouse heart developement}

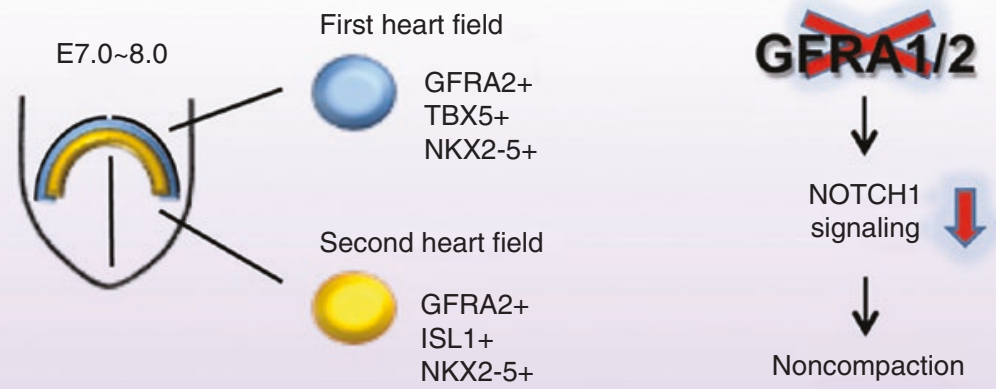

\section{Pluripotent stem cell differention}

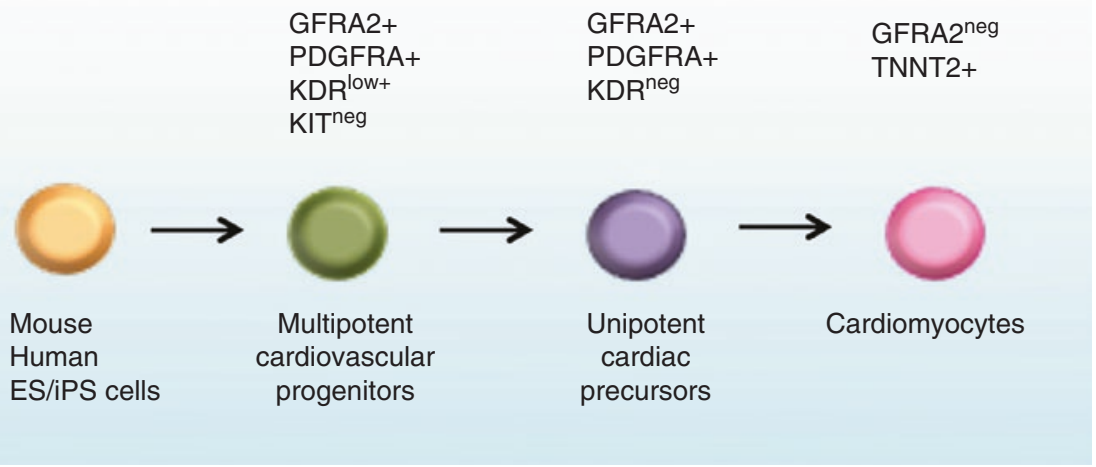

Cell Reports 2016 16, 1026-1038 DOI: (10.1016/j.celrep.2016.06.050)

Copyright @ 2016 The Author(s)

Fig. 56.1 GFRA2 is a specific marker for CPs which governs myocardial compaction. Upper case: A signal transduction via GFRA1/2 is upstream of NOTCH signal that is indispensable for the myocardial compaction process. Lower case: GFRA2 is a specific surface antigen to identify CPs from differentiating pluripotent stem cells in mice and humans. This illustration is cited from Ishida, $\mathrm{H}$ et al. Cell Rep. $2016 \mathrm{Jul}$ 26;16(4):1026-38, and is licensed under the Creative Commons Attribution 4.0 International License. To view a copy of this license, visit http://creativecommons. org/licenses/by/4.0/ or send a letter to Creative Commons, PO Box 1866, Mountain View, CA 94042, USA

- GFRA2 facilitates the isolation of CPs by fluorescence-activated cell sorting from differentiating mouse and human pluripotent stem cells. If utilizing panmesoderm marker PDGFRA and hemangioblastic marker KDR in conjunction with GFRA2, multipotent CPs giving rise to cardiomyocytes, smooth muscle cells and endothelial cells are identified as GFRA2 ${ }^{+} / \mathrm{PDGFRA}^{+} / \mathrm{KDR}^{+}$whereas CPs already committed only to cardiomyocytes are identified as GFRA $2^{+} /$ $\mathrm{PDGFRA}^{+} / \mathrm{KDR}^{\text {neg }}$. 
- In loss-of-function of Gfra2, the functional redundancy of GFRA1 compensated for the cardiac GFRA2 signal in the mutant mouse embryos. Compound mutant of Gfral/2 showed non-compaction cardiomyopathy due to the down-regulation of NOTCH signal in the developing heart. Cardiac GFRA2 signal is distinct from the canonical pathway that depends on the RET tyrosine kinase and its established ligands.

Collectively our findings establish a platform for investigating the biology of $\mathrm{CPs}$ as a foundation for the future development of CP transplantation therapies for treating heart failure.

Acknowledgments This work was supported by MRC New Investigator Research Grant G0900105 and MRC Research Grant MR/J007625/1 to K.Y., Japan Heart Foundation/Bayer Yakuhin Research Grant Abroad and JSPS (Japan Society for the Promotion of Science) Postdoctoral Fellowship for Research Abroad to H.I. We thank Ruchaya PJ at Kings College London for the support in writing.

\section{References}

1. Ishida H, Saba R, Kokkinopoulos I, et al. GFRA2 identifies cardiac progenitors and mediates cardiomyocyte differentiation in a RET-independent signaling pathway. Cell Rep. 2016;16(4):1026-38.

2. Brouilette S, Kuersten S, Mein C, et al. A simple and novel method for RNA-seq library preparation of single cell cDNA analysis by hyperactive Tn5 transposase. Dev Dyn. 2012;241(10):1584-90.

3. Kokkinopoulos I, Ishida H, Saba R, et al. Single-cell expression profiling reveals a dynamic state of cardiac precursor cells in the early mouse embryo. PLoS One. 2015;10(10):e0140831.

Open Access This chapter is licensed under the terms of the Creative Commons Attribution 4.0 International License (http://creativecommons.org/licenses/by/4.0/), which permits use, sharing, adaptation, distribution and reproduction in any medium or format, as long as you give appropriate credit to the original author(s) and the source, provide a link to the Creative Commons license and indicate if changes were made.

The images or other third party material in this chapter are included in the chapter's Creative Commons license, unless indicated otherwise in a credit line to the material. If material is not included in the chapter's Creative Commons license and your intended use is not permitted by statutory regulation or exceeds the permitted use, you will need to obtain permission directly from the copyright holder.

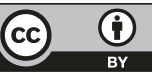

